\title{
Sustainability of Existing Cultures, Entertainment and Identity; for National Unity in A Small World
}

\author{
Edokpa Fadal Mary \\ Department Of Political Science, Faculty of Social Sciences, \\ Ambrose Alli University, Ekpoma, Edo State, Nigeria \\ Omosun Marvins Kennedy \\ Post Graduate Student, Nassarawa State University, Keffi (NSUK) \\ Department of Educational Planning and Administration (DEPA) \\ Osimen Goddy Uwa \\ Department of Political Science, Achievers University Owo
}

\begin{abstract}
The recognition of entertainment could be traced down to the peoples' way of life. It constitutes their cultural arts in satisfying human values which are reflection of the ethnical and cultural identity. This paper explains the significance of sustaining entertainment for the endowed cultures and identity in Africa for national unity. The essence of this is that ethnicity is identity which has other elements that make up cultural values. This paper concisely describes and explains the importance of enhancing popular ethics and entertainment of music and cultural arts. It is aimed at showing how entertainment can build the nation's unity by way of sustaining a popular sense of identity and recognition in terms of interest and values. It becomes imperative for any nation to take cognizance of its entertainment with a view to managing it for national unity and identification of cultures. It means that the contributions of the aesthetics of entertainment differ from nation to nation when trans-valued or compared with others. Thus, when popular entertainment meets the taste of its people's origin and beyond, it contributes to a nation's unity in diversity because the people of its origin are part of the nation whose culture encapsulate entertainment identity. It is our finding that recognition of popular entertainment and ethnic identity leads to peace and unity. This is however geared towards achieving a universal unity for peace and development through objective approach against subjective approach which has always been the trend. This paper utilizesecondary source of data.

Keywords: entertainment, culture and identity.

DOI: $10.7176 /$ RHSS/9-18-09

Publication date:September $30^{\text {th }} 2019$

\section{INTRODUCTION}

Sustaining and appreciating our cultural entity is knowledge of our cultural values and orientation. Records show that many are not ignorant of their cultural beliefs and many lay more importance to their ties of cultural background. In other words, there's an adage that says no man is an island,we all belong to one cultural background or the other. Referring to the value consensus theory of social order, this theory explains social order by reference to the notion of general commitment to common values such as traditional cultures of all kinds. They share a common sense of identity also. In the words of Masolo (1983), for a society to be stable at all, there must be a sense of general agreement among members on the basis of value orientation.

In this same tone of value consensus, there must be agreed norms through which men or the society may attain the world view of normative elements in society. For most interactions, people regard values as a given societal norms and they do not need to question them since they are socialized into them. Culture is the sum of attitudes and customs and beliefs that distinguishes one group of people from another.Culture is transmitted through languages, material objects, ritual institutions, and gifts from one generation to another or next, recognizing the existing cultures, entertainment and identity as a theme of values. It also imbibe in them the cultural values of peace, tolerance, hard work, good neighbourliness, respect for each other cultural values and constituted authorities. Political Culture refers to a commonly shared goal and acceptable rules about politics.

In an ideal society, in most cases, cultural arrangement is used to resolve conflicts as a last resort. Culture builds sense of pride, recognition, value placement, respect and a source of entertainment and pleasure. Its translation into a source of pleasure takes a process of mind-blowing ideology within other cultures and its various elements into entertainment. It strengthens beliefs and unity in a state because people react to issues based on their socialization, emotions and cultural orientation.Agidigbi (2007) defined the term "culture" as metaphorical; it is a derivation from the Latin word "cultura", meaning cultivation of the soul to which, in classic-times was compared to the cultivation of the mind. Culture at this level, was very close to civilization and as such, was seen as a conscious and teleological process, rather than a condition or an achieved state which was perceived as personal, rather than a social project.
\end{abstract}


It is seen in modern times in a number of ways, as a habit of the mind or human reflection. It is more or less the intellectual and moral development in society as a whole.

Malinowski, (2005), sees culture as partly human, partly spiritual and partly materialistic. As an embodiment of the material, psychological and moral expressions of a people; it identifies and provides them with the basis for stability and progress. In the same perspective, Uroh (1996) regards culture as the ideas that govern the lives of a people in a particular community at a particular point in time.

Porter (1972), sees it as the emulative deposit of knowledge, experience, meaning; beliefs, values, religion, concept of self, the universe and self-universe relationships, hierarchy of status, roles expectations, spatial relationships and time concept; acquired by a large group of people in the course of generation through individual and group striving.

Culture has a unique function to the society and man for stability. Its role as a vital instrument for the control and sustenance of human society was beautifully articulated by William Abraham (1962) Firstly, he sees it as the means of creating social order in society. Culture helps to prevent conflict among individuals and groups. Oladipo (1999), said that not every aspect of social life that are beyond sate control require moderation. In the same view, Abraham (1962) the regulatory role of culture is by uniting people in common beliefs and attitudes or at least in tolerance for certain beliefs, actions and values, culture fills with order that portion of life which lies beyond the pale of state intervention.

Secondary, he sees culture as an instrument for social integration. That is, it is a known social fact thata group of people or individuals are not only facilitated but their social integration is strengthened. Abraham also said that culture serves as a standard of evaluation and finally, he sees culture to its role as a regulator of change. Culture has a regulatory mechanism and that of dynamic instrument of change, this functions no doubt, is important to the survival of any human society, especially in recent times, by providing motives for human behaviour. Culture serves as an instrument for the control of change in the society. Evidently, it is an incontrovertible fact that culture is vital to the achievement of social order, peace and tranquility in any human society.

\section{Enhancing National Unity}

Enhancing national unity through the existing cultural values is one of the essential aspects of normative ethical motivation in Africa's quest for peace and stability. Echekwube's (2003) believed that the system of governance should be tied to African tradition. In other words, it is a panacea to violent conflicts and insecurity because it stresses the importance of Africa's mind towards positive attitudinal orientation that will make peace and social stability.

Thus, the mutual relationship that exists among the various ethnic groups is strengthened when cultural ties are involved. That is, no particular ethnic group is given more recognition than the other. For example, Nigeria is a big country with multiple ethnic groups. One of the strategies of maintaining unity is the general recognitionand acceptable existing norms and values of all the ethnic groups. Some may call this a constitution, but this philosophy for peace and sustainable unity lies in the alternative recognition of solidarity, compassion and having human interest in each other's cultural identity as it is related to her interest and values respectively.

Agidigbi (2012) Relating to Practical Philosophy for Peace and Stability, emphasizes wholesome human centricism or moral philosophy of altruism. Thus, an individual in his actions takes into account what he considers to be the expectations of others, and his behaviour in turn means that he expects others to act towards him in a certain way. This mutual expectations and a person's evaluation of them represents his social role. If we all take our social roles as far as the social relationships are concerned with tenacity, to the extent that we are willing and able to make personal, economic, and other sacrifices, to see it endures; and perform in our obligations therein, then there will be peace in the continent.

It is imperative to say here that putting more importance to existing cultures and entertainment gives the African people a sense and feeling of fulfillment and belonging. The feeling of inclusiveness and individual recognition is established and secured. It provides an inspiration for the past and it offers hope for the future generation of a nation. It helps to establish a nation's identity, upon which the political foundation is formed.

Towards sustaining the existing culture of our nation for peace and unity, certain policies are involved. The cultural policy that exists in most nations has helped to establish and sustain the existence in relation to cultural identities and entertainment.Oamen (2015) states that, by way of endorsing the identity of the people,their culture in theory and practice must not be ignored or despised for any political reason, recalling the experience of destructive violence and its consequences because of ignorance and feeling of neglect by some groups concerning certain values and interest, which is a reason to appreciate the diversified cultural background. When there is feeling and sense of belonging, it reduces the socio-cultural alienation between the different peoples of the world and enhances the mutual relationship that exists among the different ethnic groups. It directly or indirectly fosters joint initiatives in sustaining national unity. Thus national unity is built upon the peoples cultural values as an essential condition. 
The kind of orientation background concerning the entertainment and cultures the people have is a reflection of their attitudinal approach to certain changes that come their way. In other words, towards the achievement of peace and unity through the recognition of existing cultures and entertainment is the theme of trans-valued cultures. Experience has shown that no tribe or nation with a cultural orientation and background can support any policy not geared towards their cultural values,knowing fully well that such entertainment constitutes their cultural arts in satisfying human values which is a reflection of the ethical and cultural identity. It is the way people initiate and influence cultures and that culture influences them in a social way. The general arrangement of the people's cultures involves also, the way of solving problems of the society and the individual emotions expressed through the embodiment of his culture. Recognizing the existing cultures and entertainment is an identity of individuals' background.

It is by way of taking up cultural themes and individual emotions and presenting them in a way that makes their essential nature understandable - be it implicit or explicit in nature. In terms of societal disorder, the culture as an entertainment has its social functions in the society. It enhances stability in a society through the potentials of the state if it is well managed to improve the societal status and national identity for unity.

\section{Culture, Identity and the Traditional Approach}

We cannot successfully discuss the sustainability of existing cultures and identity without the relevant approach of the traditional perspectives. Culture itself is tradition. Tradition is more or less itself a symbol of identity. Prior to the pre-colonial administration, the problem of societal disorder was at its barest minimal, Africa had her history. The existing history however, defines her cultures. That means her way of life which in turn identified them with orientation norms and values. These norms and values in turn define their interest and attitude towards fulfilling such dreams. Man has always lived in a society known as community with an organized government regulated by laws. Africa had her own way of life that was well organized in such a way that the existing customs and cultures identify every member of the society that was generally accepted by all. In other words, the recognition of the existing cultures in line with the accepted norms and values gives a sense of belongingness to the concerned people. It is by way of identifying generality of their customs.

The belief that, our customs and traditions are outdated is a threat to our Africa existence in term of National Unity. Thus, the recognition of existing cultures and entertainment is a panacea for sustainable National Unity, peace and development. For example, when there is a crisis and the constitutional approach failed, or its yielding poor result, the traditional approach becomes relevant. This idea must be made clear that in every society in Africa, there exist traditional rulers that perform the various functions of harmonizing the peaceful coexistence of such society. Ascension to that throne is mostly by hereditary and not by democratic or political means.It means directly or indirectly, the relevance of the traditional rulers in resolving and advertising future or predicted crises is possible through the traditional approach. This is evident in the fact that an average African recognizes that there exist traditional norms and values. Any attempt to violate such rules and regulations directly or indirectly, attracts some form of sanction.

\section{The Challenges of Modernization and the Cultural Identity}

Development is expected to be based on positive policies that sustain, expand and promote our cultural norms and values. This concept recognizes that, the kind of orientation that exists in a society determines greatly the response to changes and attitudes that is displayed towards such new development. Also the growth and protection of a country is inextricably linked. Thus, the quality of the present and future life rests on the practical recognition of our cultures and entertainment, adequate planning to achieve real development without necessarily destroying or harming the cherished cultures and identity. In real sense, development should not be a curse but a blessing for the society.

Following the new world order of philosophical development without the consideration or recognizing the traditional approach is like taking two steps forward and three steps backwards, knowing fully well that a society is in dire need of peace and security for nation building, directly or indirectly will lack such development. The modernization that actually started during the colonization period in Africa also recognizes the traditional norms and values. As earlier noted, we cannot talk of modernization without the recognition of societal culture and identity. Even in some aspects of human endeavor, where it is adopted officially, it is minimal in terms of its effects. For example, relating to the social perspectives of custom and traditions, a certificate of origin is required for entrance into higher institutions. It is also required as a requirement before obtaining a job in some African countries. That is modernization in terms of transformational changes. This transformation in the political sphere may be expressed as a syndrome of related features of political modernization. It entails the capacity of a system to formulate policies and to have them carried out and the aim of such, realized through purposeful cultural orientation.

Thus, it can be said that modernization can only be given a better recognition alongside the recognition of cultures and identity. 


\section{Culture and state political unity and stability}

With the increased problems currently being faced in the continent ranging from ethnic, socio-political, security, religious and economic, there is a need to seek for immediate lasting solutions. This is because the disputants have shunned amicable options of resolution in favour of force. This problem of violence and conflict can be resolved through the cultural dimension in the continent.It establishes the restructuring of the people's mind towards positive attitudinal orientation that will make peace and social stability its basis.

The identification of culture is very important in a nation's political development. Culture and its power of state unity have also been expressed in different dimensions. It is a source of inspiration that gives the desired feelings of identity. The heritage of the people provides solace through cultural appreciations and the political stability of a nation is strengthened through cultural appreciation. For instance, the cultural policy of a state determines the extent through which it can sustain national unity. In the words of David O. (2015), it can help to establish and sustain the uniqueness and reality of all the centralized cultural policy, thereby endorsing the identity of the people whose culture in theory and practice must not be ignored or despised for political reasons. UNESCO philosophical ideas of unity and peace, believes in certain objectives which have helped to strengthen this course. These are according to Valderrama (1995), to determine the characteristic features of a country's culture and ideals; help develop in each country, sympathy and respect for other countries and for the aspiration of others; and to study and recommend appropriate measures for creating closer co-operation between nations fully respecting their ideas and their cultures.This is important so as to avert the re-occurrence of peace which eluded the world before the United Nations Education, Science and Cultural Organization (UNESCO), was established and the declaration that, "since war begins in the minds of men, it is in the minds of men that the defense of peace must be constructed. Valderrama (1995) perhaps, explains that UNESCO was established to promote peace and security through the application of culture to enhance international understanding and human welfare.

The process of development is geared towards achieving a political unity. A state is characterized by some indispensable features. In other words, culture is appreciated in different ways; different dimensions are associated with arts, way of life or lifestyles that characterized a picture of a different society. By their norms, beliefs, values and behaviours, a particular society is defined. There is no nation without a particular or peculiar feature. Basically a nation is well defined with its cultural norms and values, her diversified cultural background and interest and identity. This in turn links her national identity for unity and nation building and finally leads to general development.

Political development in this regard denotes progress towards largely indefinable end that is movement towards a closely defined objective and the ability to achieve such aim alone. It is also a social change in which ideas are introduced into a social system in order to produce higher and better co-existence among the people. It is directly an approach from the orientation perspective which in turn flows from both desired interest and values of cultural believes, knowing well that a culture has indisputable regards for life and its inhabitants.

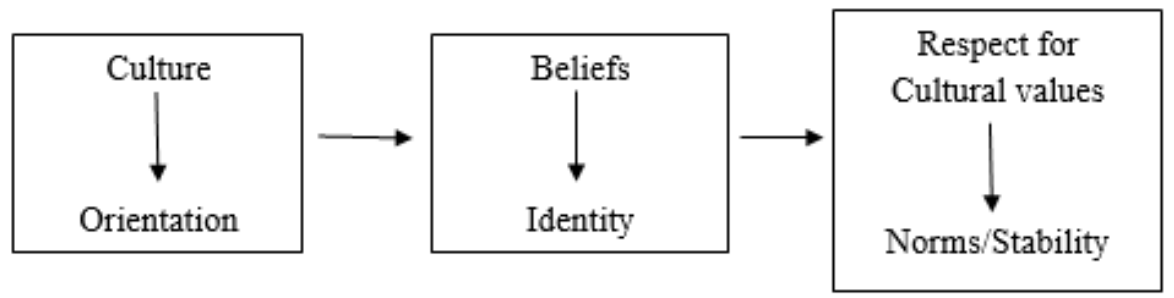

An illustrated figure of cultural development for peace and unity

Sule(1991) believes that every type of development has its social basis and character. These are identified by the various cultural elements created and fused through man's creativity, philosophy, values, ethics, order and disciplines. It further strengthened societal ability to communicate among each other for peace and unity. The sustainability of existing cultures, entertainmenst and identity for nation unity is a generalized puzzle of elements that can be attained through an accepted policy. Where cultures exist for the wellbeing of the people, orientation and behaviours is surely visible in their internalized culture.

Eteng I. A. (1998) believes that the political socialization and orientation and cultural background of a society is a life-long process. A process by which human beings transmit and learn particular thought, feeling and behavior processes and patterns required for social perpetuation of adaptation. Social transformation of culturally determined conditions and expectation, such as learning one's language, behaving according to the norms and values of culture, understanding social roles one is expected to perform as one relate to others and developing skills and techniques with which to adapt to, as well as transform one's social and physical environments.

Human beings have always liked to indentify fundamental and environment interest to a sense of belonging, 
to shared cultural and ethnic idea and values, to a way of life with fundamental influence and determine his socio-political believes and behavior. The orientation beliefs determines the kind and level of identity that will be pursued. That is the kind of interest and a value determine the cultural orientation and believes. A society that emphasizes on cultural orientation of protocol and order, can easily resolve any crises of issues through traditional approach for unity. Once there are beliefs and feelings of protection and recognition of personal identity, it further leads to respect for cultural values. It also leads to further respect for societal norms and ethical regulation. The end result is self-respect for societal unity and stability for nation building and unity.

It strengthens love between each other's beliefs and culture which in turn leads to general development in terms of its social, political, economic and technological benefits.

\section{Suggestions}

What should be done is to strive for the ability to project some methods through the traditional approach to reduce the rate of ethnic crises. Recalling the pre-colonial era before the coming of the colonial era that developed into modern political and societal order, there was the existence of a traditional political system.

Generally, no particular ethnic group harbours evil, which means it is possible to achieve national unity through the traditional approach.

\section{Conclusion}

The fact that cultures and identity existence in the traditional setting of any nation are established norms and values, the traditional approach of human values and recognition of identity is a symbol of unity.

We can re-unite ourselves once again by giving each ethnic group the benefits of identity and recognition of her cultural background. Ethnic crises can be controlled through various means. More so, the adverse effect of modernization process without culture and identity and recognition lacks in many ways, mutual respect for each other cultures or traditions and making it at all expense is the order of the day. In other words, wealth is valued more than moral and cultural values for peaceful co-existence. A society that lacks a traditional control or moral values at the grass root level can be said to be a decaying society.

The foregoing discussion is evidence which shows or explains the importance of sustainability of existing cultures, entertainment and identity for national unity. It seems most useful to consider the future of development in any society or nation, emanating from enhanced cultures, entertainment and identity through orientation background. Embracing these aspects of human development implies taking people's worldviews seriously and following an integral approach in the development process of unity. It emphasized that development in terms of sustainable unity and peace for a nation, should not be viewed in a unilateral dimension alone rather, in a universal or multilateral perspectives. This paper established the fact that sustaining existing cultures, entertainment and identity for nation unity is a step of development that has to be embraced. It is a means of infusing various cultural values into one in defense of nature hood. It is a medium of approval for peace and unity for nation building. It is a means of identity through a collection of individual cultures which emanates from the foundation of a nation.

Culture is directly or indirectly a reflection of identity and orientation background. The artist soberly examines the activities of its immediate society and nation and input them in his or her entertainment content whichis in turn expresses through different styles and performance in their industries. Arts and culture is an expression of orientation beliefs, ideas and values that exist from one generation to another. It is displayed attitude of cultural norms and sustainability of traditional values. Sustainability of existing cultures, entertainment and identity; for nation unity is by way of securing the heritage of a people which provides solace through inspiration when they are threatened by circumstances for sustainable peace and unity.

Culture has to be seen as the core ingredients of continental peace and harmony. It should not be seen as inselective return to the past; rather, it is a critical, humane and foundational appropriation of peaceful resolution of conflict for peace, love and stability for states.

\section{REFERENCES}

Abraham, W. (1962). The mind of Africa: Weidenfeld and Nicolson.

Aghemelo, T. A. and O. Osumah (2003) Inputs and Conduuits of Political Behaviour. Akure: Sylva Publishing Inc, (2005)

Agidigbi, B.O. (2007). The relevance of African culture to conflict resolution in Africa. Realize printers, Benin City, Nigeria. Page 85-90

Deutsch. E. (ed) (1991). Culture and modernity east west philosophic perspective. Honolulu: Hawaii Press.

Echekwude, A. O. (1994). An Introduction to African Philosophy, Ibadan: Kraft Books Ltd.

Ede, S.W. (2005). "Circum-Development Integration and the Future of Africa". In Enwisdomisation Journal, Vol. 2, Number 3.

Eteng I. A (1998), "Readings in Social Sciences: Issues in National Development”. Enugu: Gourth Dimension 
Publishing Company Limited.

Masolo, D.A. (1983). Philosophy and Culture, Odera, H.O and Masolo, D.A. (eds.) Nairobi: Bookwise.

David, O. (2015), International Journal Of Governance and Development, Volume 4, Number 2, July, 2015. p. 223

Oladipo, O. (1999). "Philosophy and culture" in Ayo F. (ed), Philosophy and Society. Ibadan: Hope Publications.

Porter, R. (1972). "An overview of Intercultural Communication" in Samorca, L.A \& Porter, R. (eds) Intercultural Communications: A Reader. California: Wadasorth Publishing Co.

Sule, Bello, (1991). Cultural Management as a strategy for national development. NCAC: Lagos.

UNESCO. (1988). Culture:Apractical guide to the world decade for development. Paris: UNESCO.

Uroh, C. O. (1996). "Africa in the Philosophy Of Culture: Demystifying an Ideology of Cultural Imperialism", in Journal of Philosophy and Development. Volume 2, Nos 1 and 2.

Vallederrama, Fernando. (1995) A history of UNESCO. Paris: UNESCO 